\title{
EMPREGO DO CARVÃO ATIVADO PARA REMOÇÃo DE COBRE EM CACHAÇA
}

Annete de J. Boari Lima*, Maria das Graças Cardoso, Mário César Guerreiro e Flávio Araújo Pimentel

Departamento de Química, Universidade Federal de Lavras, CP 37, 37200-000 Lavras - MG

Recebido em 9/3/05; aceito em 5/7/05; publicado na web em 20/1/06

\begin{abstract}
USING ACTIVATED CARBON TO REMOVE COPPER FROM SUGAR CANE SPIRIT. Copper content is of great concern among sugarcane-spirit producers. It is released from copper-made distillers, during the distillation process. Activated carbon has been used to remove copper. However, depending on the amount of carbon and the duration of reaction, it can also remove higher alcohols and esters, which are important in the final product. A sugarcane spirit with $9 \mathrm{mg} \mathrm{L}^{-1}$ of copper was shaken with 2 to $26 \mathrm{~g} \mathrm{~L}^{-1}$ of activated carbon, during 10 to 1440 minutes. Then, copper and organic compounds were measured. At least $12 \mathrm{~g} \mathrm{~L}^{-1}$ of carbon and $60 \mathrm{~min}$ shaking time were necessary to decrease copper bellow $5 \mathrm{mg} \mathrm{L}^{-1}$. However, other components of the product were also affected.
\end{abstract}

Keywords: sugar cane spirit; activated carbon; adsorption.

\section{INTRODUÇÃO}

Bebida obtida por destilação do mosto fermentado de cana-deaçúcar, a aguardente de cana, caninha ou cachaça deve seguir alguns padrões de qualidade importantes para o consumo. A cachaça é a segunda bebida mais consumida pelos brasileiros. Estima-se o consumo de 70 milhões de doses diárias, o que representa, em média, aproximadamente $6 \mathrm{~L}$ (habitante ano $^{-1}$ ). Dados oficiais apontam uma produção de 1,6 bilhão de L por ano, sendo $90 \%$ de cachaça industrial e $10 \%$ de cachaça artesanal.

O Governo Federal decidiu considerar a cachaça uma bebida genuinamente brasileira desencadeando, com isso, um processo de valorização da bebida com o objetivo de estimular o aumento de produção e a melhoria de qualidade visando a ampliação do mercado externo. A meta do Brasil é exportar 10 milhões de L. Minas Gerais tem capacidade para suprir $10 \%$ desse montante ${ }^{1}$. Além do aumento de produção, o mercado tem feito crescer a preocupação com a qualidade da bebida ${ }^{2}$. A cachaça produzida em alambiques de cobre tem grande procura pelo sabor e pela forma artesanal como é produzida $^{3}$. Entretanto, a quantidade de cobre nesta cachaça tem sido motivo de preocupação. Originado durante o processo de destilação, esse elemento tem seu limite máximo estabelecido em $5 \mathrm{mg} \mathrm{L}^{-1}$, de acordo com o Ministério da Agricultura, Pecuária e Abastecimento (MAPA $)^{4}$. Durante o processo de destilação, ou durante o tempo em que o alambique não está em uso, há formação de "azinhavre" (carbonato básico de cobre) nas paredes internas. Essa mistura solúvel $\left[\mathrm{CuCO}_{3}, \mathrm{Cu}(\mathrm{OH})_{2}\right]$ é dissolvida pelos vapores alcoólicos ácidos, sendo responsável pela contaminação da bebida ${ }^{5}$. Apesar de possuir odores mais agradáveis do que os verificados em aguardentes destiladas em alambiques de aço inox, a cachaça produzida em alambiques de cobre pode provocar problemas à saúde, quando este elemento ocorre em concentrações elevadas ${ }^{6}$.

O cobre é um metal essencial à saúde humana, estando presente em todos os fluidos e muitos tecidos humanos. Esse elemento, juntamente com aminoácidos, ácidos graxos e vitaminas, é necessários para os processos metabólicos.

$\mathrm{O}$ excesso de cobre pode ser tóxico por causa da afinidade do metal com grupos S-H de muitas proteínas e enzimas, sendo asso- ciado a doenças como epilepsia, melanoma e artrite reumatóide, bem como à perda de paladar ${ }^{7}$.

Esse excesso pode ser reduzido com a limpeza apropriada do alambique, bastando, para isso, fazer uma primeira destilação com água ou com água e caldo de limão, cujo vapor arrasta o azinhavre das paredes do alambique de cobre. Entretanto, muitos produtores não atentam para essa medida e preferem fazer uso de filtros de resina de troca iônica ou de carvão ativado, após a destilação, para eliminar o excesso de cobre na cachaça. Uma das formas mais econômicas de se remover o excesso de cobre da cachaça é o emprego de substâncias como o carvão ativado. Porém, durante o processo de remoção do cobre, outros produtos podem também ser adsorvidos pelo carvão ou resina e serem removidos da cachaça.

Assim, os objetivos deste trabalho foram avaliar a influência da quantidade de carvão ativado e do tempo de agitação na remoção de cobre e outros componentes da cachaça; determinar a quantidade de carvão ativado e o tempo de agitação que promova a retirada eficiente de cobre, sem comprometer a qualidade da cachaça.

\section{PARTE EXPERIMENTAL}

Para simulação de níveis elevados de cobre, 9 L de cachaça contendo cerca de $1 \mathrm{mg} \mathrm{L}^{-1}$ de cobre foram armazenados em um pequeno alambique de cobre por um tempo aproximado de $30 \mathrm{~h}$, fortificando-se a cachaça com cobre. Posteriormente, o volume foi completado para $40 \mathrm{~L}$ com a cachaça original. O teor final de cobre foi de cerca de $9 \mathrm{mg} \mathrm{L}^{-1}$.

Para o ensaio de sorção, empregou-se o carvão nas concentrações de 2, 4, 12 e $26 \mathrm{~g} \mathrm{~L}^{-1}$ e tempos de agitação de 10, 30, 60, 360, 720 e 1440 min. Foi utilizado carvão ativado em pó comercial (Chemco, lote 10698). Após agitação, foi feita a filtração a vácuo com papel de filtro para eliminação do carvão. Uma fração de cada amostra foi submetida à análise de cobre e acidez volátil e o restante foi submetido à destilação para dosagem de ésteres, álcoois superiores, aldeídos, grau alcoólico e metanol. As determinações foram feitas seguindo as especificações estabelecidas pelo Decreto 2314 de 04/09/1997, artigo 91 (MAPA), como seguem:

a) metanol: foi quantificado através de medidas espectrofotométricas, realizadas na região visível $(575 \mathrm{~nm})$ e comparadas com valores de absorbâncias estabelecidos através de uma curva de calibração construída com soluções padrão etanol/

*e-mail: anneteboari@msn.com 
metanol, contendo quantidades conhecidas de metanol;

b) teor alcoólico: foi determinado destilando-se, inicialmente, $220 \mathrm{~mL}$ de uma mistura 1:10 água/aguardente. Após destilação, diluiram-se $150 \mathrm{~mL}$ do produto da destilação com $50 \mathrm{~mL}$ de água. O teor alcoólico foi obtido a partir de medidas feitas a $20^{\circ} \mathrm{C}$, com auxílio de um alcoômetro, e os resultados expressos em \% v/v de etanol;

c) álcoois superiores: a quantidade total foi determinada através de medidas espectrofotométricas efetuadas na região visível do espectro $(540 \mathrm{~nm})$. Essa quantificação foi realizada através da comparação com uma curva de calibração construída utilizando-se uma mistura de álcoois superiores solubilizada em solvente água/etanol;

d) acidez volátil: foi determinada através da extração dos ácidos voláteis utilizando-se técnicas de arraste a vapor d'água. O extrato obtido foi titulado através de métodos de titulação ordinários. Os resultados dessas análises foram expressos em $\mathrm{g}$ de ácido acético para $100 \mathrm{~mL}$ da amostra ou para $100 \mathrm{~mL}$ de álcool anidro;

e) aldeídos: foram dosados através de métodos iodimétricos, titulando-se $\mathrm{o} \mathrm{SO}_{2}$ produzido durante a sequiência de reações do processo analítico. A quantidade de aldeídos presentes nas amostras é expressa em g de aldeído acético para $100 \mathrm{~mL}$ de álcool anidro;

f) ésteres: foram determinados através de titulação dos ácidos carboxílicos obtidos por trans-esterificação dos ésteres, sendo os resultados expressos em $\mathrm{g}$ de acetato de etila para $100 \mathrm{~mL}$ de álcool anidro e,

g) cobre: foi realizada por meio de medidas espectofotométricas, em $546 \mathrm{~nm}$ na região visível. As quantidades de cobre foram determinadas por comparação das absorbâncias observadas na amostra de cachaça com valores de absorbâncias referentes a uma curva de calibração previamente construída, utilizando-se sulfato de cobre pentaidratado como padrão.

Os teores dos álcoois superiores propanol, butanol, isobutílico, amílico e isoamílico, para obtenção da relação entre os mesmos, foram obtidos por cromatografia em um cromatógrafo a gás, Hewlett-Packard 6890, equipado com injetor automático "splitsplitless", detector de ionização de chama (FID), coluna HPInnonwax $(25 \mathrm{~m} \mathrm{x} \mathrm{0,20} \mathrm{mm}$ x 0,2 $\mu \mathrm{m})$. As temperaturas foram de 160 e $180{ }^{\circ} \mathrm{C}$ para o injetor e o detector, respectivamente. $\mathrm{O}$ forno foi programado da seguinte maneira: $40^{\circ} \mathrm{C}(2,5 \mathrm{~min})$ subindo $5^{\circ} \mathrm{C}$ $\min ^{-1}$ até $120^{\circ} \mathrm{C}(15 \mathrm{~min})$. $\mathrm{O}$ volume de amostra injetado foi de $1 \mu \mathrm{L}$; a taxa de split foi de 1:100; o gás de arraste foi nitrogênio sob 1.322 bar de pressão, fluxo de $1,1 \mathrm{~mL} \mathrm{~min}^{-1}$. As áreas de picos das amostras foram comparadas a áreas de reagentes PA da marca Merck, empregados como padrão de comparação. Uma curva padrão foi traçada utilizando-se propanol, butanol, álcool isobutílico, álcool amílico e isoamílico.

$\mathrm{O}$ delineamento experimental utilizado foi inteiramente casualizado, com quatro repetições. Os tratamentos foram dispostos em um esquema fatorial ( 4 x 6), sendo constituídos pelas combinações entre quantidades de carvão (2, 4, 12 e $26 \mathrm{~g} \mathrm{~L}^{-1}$ de cachaça) e os tempos de agitação (10, 30, 60, 360, 720 e 1440 min). A análise estatística foi feita empregando-se o programa SISVAR ${ }^{8}$, sendo as médias de 4 repetições comparadas pelo teste de Scott-Knott, em nível de $5 \%$ de probabilidade.

\section{RESULTADOS E DISCUSSÃO}

Considerando que, geralmente, amostras de cachaça contendo cobre em excesso apresentam teores de 8 a $10 \mathrm{mg} \mathrm{L}^{-1}$, os experi- mentos foram conduzidos com amostras de cachaça contendo cerca de $9 \mathrm{mg} \mathrm{L}^{-1}$ do metal.

A Figura 1 mostra os resultados referentes à análise de cobre nas amostras. $\mathrm{O}$ tempo zero refere-se à amostra na condição inicial e será empregada como sendo o controle.

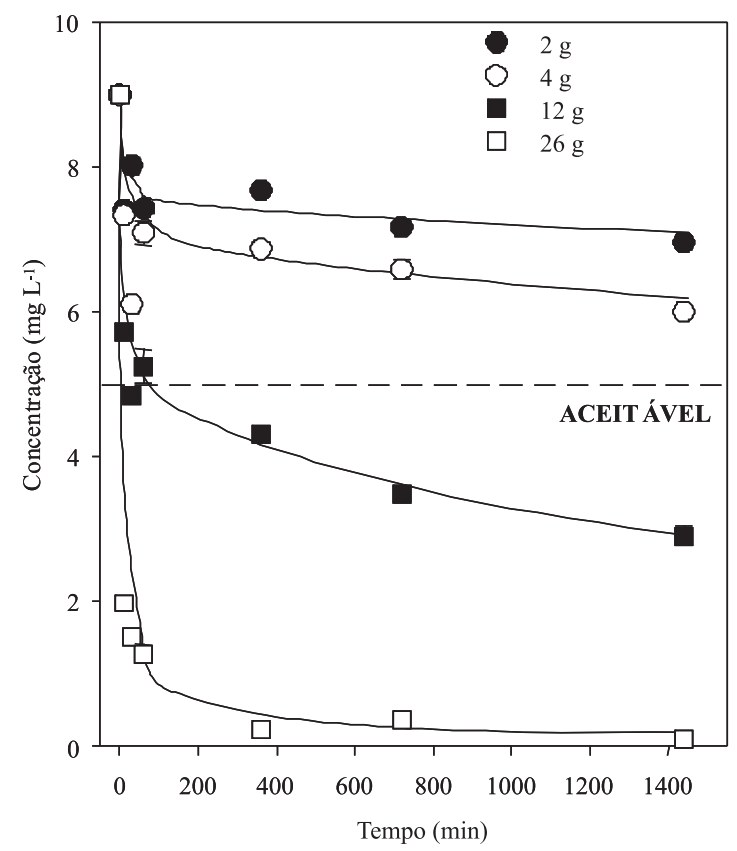

Figura 1. Influência da concentração de carvão ativado e do tempo de agitação na extração de cobre de cachaça

Observa-se variação da concentração de cobre nos tempos testados seguindo uma tendência de diminuição da concentração de cobre com o aumento do tempo de exposição. Esse efeito do tempo de agitação foi mais pronunciado para as maiores concentrações de carvão. As quantidades de 12 e $26 \mathrm{~g} \mathrm{~L}^{-1}$ foram mais eficientes na remoção de cobre. Assim, uma cachaça com níveis de cobre em torno de $9 \mathrm{mg} \mathrm{L}^{-1}$, após exposição a $12 \mathrm{~g} \mathrm{~L}^{-1}$ de carvão ativado por $360 \mathrm{~min}$, estaria dentro dos padrões estabelecidos pelo MAPA quanto à dosagem de cobre (máximo $5 \mathrm{mg} \mathrm{L}^{-1}$ ). $\mathrm{O}$ mesmo ocorre na presença de $26 \mathrm{~g} \mathrm{~L}^{-1}$ mas com tempo de agitação apenas de $10 \mathrm{~min}$, demonstrando maior eficiência na extração de cobre.

Diferentemente da quantidade de cobre, o grau alcoólico não foi afetado pela quantidade ou tempo de agitação, conforme pode ser observado na Tabela 1. Isso se deve ao fato do carvão ativado estar em quantidade pequena em relação ao etanol. As variações encontradas estão dentro do erro experimental, pois para a maior quantidade de carvão ativado utilizado espera-se adsorver cerca de

Tabela 1. Grau alcoólico $\left({ }^{\circ} \mathrm{GL}\right)$ em cachaça de alambique após tratamento com carvão em diferentes quantidades e tempos de contato

\begin{tabular}{rcccc}
\hline Tempo (min) & \multicolumn{4}{c}{ Quantidade de carvão $\left(\mathrm{g} \mathrm{L}^{-1}\right)$} \\
& 2 & 4 & 12 & 26 \\
\hline 0 & 38,0 & 38,0 & 38,0 & 38,0 \\
10 & 37,2 & 38,0 & 38,5 & 38,0 \\
30 & 38,0 & 37,0 & 38,0 & 36,5 \\
60 & 38,0 & 37,5 & 37,5 & 37,5 \\
360 & 38,0 & 37,0 & 38,0 & 37,0 \\
720 & 37,5 & 38,0 & 38,5 & 38,0 \\
1440 & 38,0 & 38,0 & 38,0 & 38,0 \\
\hline
\end{tabular}


0,5\% de etanol, considerando-se que a adsorção máxima está em cerca de $60 \mathrm{mg}$ de etanol por g de carvão ativado.

A acidez volátil da cachaça, originada do ácido acético, é mostrada na Tabela 2. Neste caso, pode ser observado um significativo efeito na concentração, reduzindo a acidez da cachaça. $\mathrm{O}$ efeito de tempo de contato foi mais pronunciado com maiores quantidades de carvão ativado, mostrando que a reação de remoção da acidez ocorre rapidamente, sendo dependente somente da disponibilidade de superfície para adsorção.

Tabela 2. Acidez volátil (mg $\left.100 \mathrm{~mL}^{-1}\right)$ em cachaça de alambique após tratamento com carvão em diferentes tempos de contato

\begin{tabular}{rcccc}
\hline Tempo (min) & \multicolumn{4}{c}{ Quantidade de carvão $\left(\mathrm{g} \mathrm{L}^{-1}\right)$} \\
& 2 & 4 & 12 & 26 \\
\hline 0 & 43,30 & 43,30 & 43,30 & 43,30 \\
10 & 48,38 & 37,22 & 35,85 & 18,15 \\
30 & 45,39 & 42,88 & 33,59 & 18,78 \\
60 & 44,40 & 43,27 & 31,27 & 18,29 \\
360 & 45,39 & 43,83 & 29,05 & 14,92 \\
720 & 46,07 & 41,76 & 28,68 & 18,15 \\
1440 & 47,36 & 39,94 & 28,86 & 10,89 \\
\hline
\end{tabular}

O principal aldeído encontrado na cachaça é o acetaldeído. Os dados encontrados para aldeídos estão mostrados na Tabela 3. A exemplo do que ocorreu com o grau alcoólico, praticamente não houve variação na quantidade de aldeídos da cachaça. Os aldeídos, tendo características polares, competem pelos sítios com os mais polares, como água, etanol (em maior quantidade) e ácidos, não sendo, desta maneira, preferencialmente adsorvidos.

Tabela 3. Concentração de aldeídos ( $\left.\mathrm{mg} 100 \mathrm{~mL}^{-1}\right)$ em cachaça de alambique após tratamento com carvão em diferentes tempos de contato

\begin{tabular}{rcccc}
\hline Tempo (min) & \multicolumn{4}{c}{ Quantidade de carvão $\left(\mathrm{g} \mathrm{L}^{-1}\right)$} \\
& 2 & 4 & 12 & 26 \\
\hline 0 & 15,07 & 15,07 & 15,07 & 15,07 \\
10 & 16,29 & 16,17 & 16,63 & 13,26 \\
30 & 15,78 & 16,70 & 15,65 & 14,14 \\
60 & 17,10 & 15,21 & 17,46 & 14,04 \\
360 & 15,93 & 15,17 & 14,31 & 13,03 \\
720 & 17,04 & 13,86 & 13,75 & 13,01 \\
1440 & 16,81 & 13,11 & 13,99 & 13,19 \\
\hline
\end{tabular}

Os ésteres, responsáveis pelo aroma típico, agradável e suave que a cachaça adquire com o envelhecimento, têm como principal representante o acetato de etila que em pequenas quantidades incorpora um aroma agradável de frutas, mas em grandes quantidades confere à cachaça um sabor enjoativo e desagradável ${ }^{9}$. A concentração de carvão teve influência significativa na quantidade de ésteres, conforme mostrado na Tabela 4. Não houve efeito significativo do tempo de agitação na quantidade de éster da cachaça, dentro de uma mesma concentração de carvão, após $10 \mathrm{~min}$. Observa-se que os ésteres são bastante adsorvidos pelo carvão ativado, havendo uma boa correlação linear entre a adsorção de ésteres e a quantidade de carvão ativado empregado, sendo a adsorção na taxa de $1,47 \mathrm{mg}$ de ésteres por $\mathrm{g}$ de carvão ativado adicionado $\left(\mathrm{r}^{2}=\right.$ 0,98). Esta adsorção provavelmente se deve à característica apolar dos ésteres, que os torna suscetíveis à adsorção. Como estes são importantes na formação do aroma e sabor da cachaça, pode-se dizer que a qualidade desta sofrerá uma depreciação se forem utilizadas quantidades superiores a $4 \mathrm{~g} \mathrm{~L}^{-1}$ de carvão ativado.
Estando a concentração de metanol na amostra inicial muito baixa, não foi possível discutir a interferência do carvão ativado sobre o mesmo, uma vez que as leituras em absorbâncias ficaram abaixo do limite de detecção do aparelho.

Tabela 4. Concentração de ésteres $\left(\mathrm{mg} 100 \mathrm{~mL}^{-1}\right)$ em cachaça de alambique após tratamento com carvão em diferentes tempos de contato

\begin{tabular}{rcccc}
\hline Tempo (min) & \multicolumn{4}{c}{ Quantidade de carvão $\left(\mathrm{g} \mathrm{L}^{-1}\right)$} \\
& 2 & 4 & 12 & 26 \\
\hline 0 & 46,45 & 46,45 & 46,45 & 46,45 \\
10 & 42,44 & 42,61 & 21,03 & 8,70 \\
30 & 45,85 & 42,72 & 21,30 & 9,00 \\
60 & 41,26 & 44,74 & 21,60 & 8,77 \\
360 & 42,41 & 43,43 & 27,69 & 9,03 \\
720 & 42,70 & 37,28 & 24,17 & 9,79 \\
1440 & 39,74 & 38,88 & 27,51 & 9,25 \\
\hline
\end{tabular}

Os álcoois superiores mais comumente encontrados em cachaça são propanol, butanol, isobutanol, amílico e isoamílico. Conforme se verifica na Tabela 5, tanto a concentração de carvão ativado quanto o tempo de agitação proporcionaram diferenças significativas nos teores de álcoois superiores totais. Houve forte adsorção logo nos $10 \mathrm{~min}$ e na concentração de $2 \mathrm{~g} \mathrm{~L}^{-1}$. A partir desse tempo e concentração, não houve consistência suficiente nos valores para apontar uma tendência na adsorção em resposta à concentração e tempo, podendo ter ocorrido um equilíbrio ou saturação do carvão ativado.

Tabela 5. Concentração de álcoois superiores $\left(\mathrm{mg} 100 \mathrm{~mL}^{-1}\right) \mathrm{em}$ cachaça de alambique após tratamento com carvão em diferentes tempos de contato

\begin{tabular}{rcccc}
\hline Tempo (min) & \multicolumn{4}{c}{ Quantidade de carvão $\left(\mathrm{g} \mathrm{L}^{-1}\right)$} \\
& 2 & 4 & 12 & 26 \\
\hline 0 & 224,12 & 224,12 & 224,12 & 224,12 \\
10 & 171,41 & 146,46 & 192,94 & 163,91 \\
30 & 154,58 & 146,98 & 184,65 & 189,59 \\
60 & 151,71 & 135,93 & 168,01 & 144,75 \\
360 & 173,79 & 144,39 & 129,03 & 166,64 \\
720 & 172,59 & 149,30 & 131,46 & 161,87 \\
1440 & 186,94 & 150,21 & 124,67 & 154,80 \\
\hline
\end{tabular}

A soma dos compostos secundários (Tabela 6) não pode ultrapassar $650 \mathrm{mg} / 100 \mathrm{~mL}$ nem ficar abaixo de $200 \mathrm{mg} / 100 \mathrm{~mL}$. Valores muito altos ou muito baixos representam cachaça de qualidade inferior.

Observa-se que os valores das somas dos compostos secundários sofrem diminuição significativa a partir de $4 \mathrm{~g} \mathrm{~L}^{-1}$ de carvão

Tabela 6. Soma dos compostos secundários em cachaça de alambique após tratamento com carvão em diferentes tempos de contato

\begin{tabular}{rcccc}
\hline Tempo (min) & \multicolumn{4}{c}{ Quantidade de carvão $\left(\mathrm{g} \mathrm{L}^{-1}\right)$} \\
& 2 & 4 & 12 & 26 \\
\hline 0 & 328,94 & 328,94 & 328,94 & 328,94 \\
10 & 278,55 & 253,57 & 266,46 & 204,05 \\
30 & 261,62 & 249,30 & 255,20 & 231,53 \\
60 & 254,49 & 239,15 & 238,35 & 185,86 \\
360 & 277,53 & 246,84 & 200,10 & 203,64 \\
720 & 278,42 & 242,21 & 198,08 & 202,84 \\
1440 & 290,86 & 242,16 & 195,05 & 188,15 \\
\hline
\end{tabular}


ativado. Tal diminuição é progressiva com o aumento do tempo de exposição e aumento da quantidade de carvão, sendo que após 360 min os resultados já não mostram diferença estatística. Lembrando que valores abaixo de $200 \mathrm{mg} / 100 \mathrm{~mL}$ são considerados fora dos padrões ${ }^{3}$, o emprego de $12 \mathrm{~g} \mathrm{~L}^{-1}$ de carvão ativado em exposição por mais de $360 \mathrm{~min}$, ou de $26 \mathrm{~g} \mathrm{~L}^{-1}$ por mais de $720 \mathrm{~min}$, situaria a cachaça fora dos padrões de qualidade.

\section{Razão entre álcoois superiores}

A solubilidade dos álcoois diminui com o aumento da cadeia carbônica (número de átomos de carbono) e a adsorção pelo carvão ativado aumenta à medida que a solubilidade em água diminui. Por essa razão, análises cromatográficas foram realizadas para avaliação da proporção entre os álcoois propanol, butílico, isobutílico e isoamílico. Nas amostras foram encontrados apenas três álcoois em quantidades suficientes para quantificação: propanol, álcool isobutílico e o álcool isoamílico, sendo o último encontrado em maior quantidade (tempo de retenção de 8,64 min).

$\mathrm{O}$ álcool isoamílico foi relativamente mais adsorvido do que o propanol (Tabela 7). Observou-se que houve aumento da relação propanol/álcool isoamílico em função da quantidade de carvão ativado e do tempo de agitação. Para as concentrações de 12 e 26 g, a diferença na relação é significativa a partir dos $10 \mathrm{~min}$. Este fato se deve à cadeia maior e relativamente menos polar do álcool isoamílico, o que confere ao mesmo maior afinidade com a superfície do carvão ativado. Não há diferença significativa para as concentrações 2 e $4 \mathrm{~g} \mathrm{~L}^{-1}$ de carvão ativado.

Tabela 7. Relação entre propanol e álcool isoamílico em cachaça de alambique após tratamento com carvão em diferentes tempos de agitação

\begin{tabular}{rcccc}
\hline Tempo (min) & \multicolumn{4}{c}{ Quantidade de carvão $\left(\mathrm{g} \mathrm{L}^{-1}\right)$} \\
& 2 & 4 & 12 & 26 \\
\hline 0 & 0,345 & 0,345 & 0,345 & 0,345 \\
10 & 0,361 & 0,351 & 0,373 & 0,440 \\
30 & 0,357 & 0,357 & 0,373 & 0,442 \\
60 & 0,339 & 0,350 & 0,385 & 0,445 \\
360 & 0,351 & 0,357 & 0,394 & 0,447 \\
720 & 0,335 & 0,353 & 0,395 & 0,459 \\
1440 & 0,333 & 0,353 & 0,399 & 0,479 \\
\hline
\end{tabular}

Por se tratar de uma cadeia carbônica menor que a cadeia do álcool isoamílico, o álcool isobutílico foi relativamente menos adsorvido. Os resultados na Tabela 8 mostram menor alteração na proporção de propanol/isobutílico que na de propanol/isoamílico mostrada na Tabela 7. Entretanto, o álcool isobutílico ainda foi

Tabela 8. Relação entre a concentração de propanol e álcool isobutílico em cachaça de alambique após tratamento com carvão em diferentes tempos de contato

\begin{tabular}{rrrrr}
\hline Tempo (min) & \multicolumn{4}{c}{ Quantidade de carvão $\left(\mathrm{g} \mathrm{L}^{-1}\right)$} \\
& 2 & 4 & 12 & 26 \\
\hline 0 & 1,156 & 1,156 & 1,156 & 1,156 \\
10 & 1,194 & 1,199 & 1,183 & 1,228 \\
30 & 1,180 & 1,156 & 1,186 & 1,249 \\
60 & 1,201 & 1,155 & 1,197 & 1,235 \\
360 & 1,185 & 1,186 & 1,208 & 1,189 \\
720 & 1,117 & 1,171 & 1,201 & 1,215 \\
1440 & 1,137 & 1,167 & 1,200 & 1,261 \\
\hline
\end{tabular}

relativamente mais adsorvido que o propanol, o que causou elevação da relação entre estes dois álcoois quando as amostras receberam $26 \mathrm{~g}$ de carvão.

A maior adsorção do álcool isoamílico relativamente ao álcool isobutílico pode também ser observada na Tabela 9. As diferenças foram maiores nesta relação que na relação propanol/isobutílico. A maior adsorção do álcool isoamílico foi observada a partir da concentração de $12 \mathrm{~g} \mathrm{~L}^{-1}$ e $10 \mathrm{~min}$ de exposição, indicando que o álcool isoamílico, por apresentar menor polaridade (cadeia maior e ramificada), é adsorvido preferencialmente.

Tabela 9. Relação entre a concentração de álcool isobutílico e álcool isoamílico, em cachaça de alambique após tratamento com carvão em diferentes tempos de contato

\begin{tabular}{rcccc}
\hline Tempo (min) & \multicolumn{4}{c}{ Quantidade de carvão $\left(\mathrm{g} \mathrm{L}^{-1}\right)$} \\
& 2 & 4 & 12 & 26 \\
\hline 0 & 0,299 & 0,299 & 0,299 & 0,299 \\
10 & 0,302 & 0,293 & 0,316 & 0,359 \\
30 & 0,302 & 0,309 & 0,315 & 0,354 \\
60 & 0,283 & 0,303 & 0,322 & 0,360 \\
360 & 0,296 & 0,301 & 0,326 & 0,376 \\
720 & 0,300 & 0,301 & 0,329 & 0,377 \\
1440 & 0,294 & 0,302 & 0,333 & 0,380 \\
\hline
\end{tabular}

\section{CONCLUSÕES}

O carvão ativado mostrou-se eficiente na remoção do cobre, sendo $12 \mathrm{~g} \mathrm{~L}^{-1}$ e tempo acima de 60 min mais recomendados para uma cachaça cujos teores de cobre estejam próximos a $9 \mathrm{mg} \mathrm{L}^{-1}$.

As quantidades de 12 e $26 \mathrm{~g} \mathrm{~L}^{-1}$ alteraram as proporções dos álcoois propanol, isobutílico e isoamílico em cachaça.

Tanto a quantidade quanto o tempo de agitação influenciaram significativamente a acidez volátil, os álcoois superiores e os teores de ésteres, a partir de $4 \mathrm{~g} \mathrm{~L}^{-1}$ e 10 min de agitação.

A redução nos teores de aldeídos foi menos acentuada que a redução na concentração de ésteres, sendo os aldeídos afetados somente nas concentrações 12 e $26 \mathrm{~g} \mathrm{~L}^{-1}$.

O carvão ativado deve ser usado com cautela, para que compostos orgânicos responsáveis pelo aroma e sabor da cachaça não sejam também removidos em quantidades que venham a depreciar a bebida.

\section{AGRADECIMENTOS}

Ao Alambique JM pelas cachaças gentilmente fornecidas, utilizadas nesse trabalho. Ao $\mathrm{CNPq}$ pela ajuda financeira.

\section{REFERÊNCIAS}

1. Sebrae-MG; Estado de Minas-Economia 2002, 48, 48.

2. Nonato, E. A.; Carazza, F. C. S.; Carvalho, C. R.; Cardeal, Z. L.; J. Agric. Food Chem. 2001, 49, 3529.

3. Cardoso, D. R.; Lima-Neto, B. S.; Franco. D. W.; Quim. Nova 2003, 26, 165.

4. BRASIL. Ministério da Agricultura, Pecuária e Abastecimento, Decreto n. 2314 de 04/09/1997.

5. Lima- Neto, B. S.; Bezerra, C. W. B.; Polastro, L.; Campos, P.; Nascimento, R. F.; Furuya, S. M. B.; Franco, D. W.; Quim. Nova 1994, 17, 220.

6. Faria, J. B. A.; Tese de Doutorado, Universidade Estadual de São Paulo, Brasil, 1989.

7. Sargentelli, V.; Quim. Nova 1996, 19, 290.

8. Ferreira, D. F.; Sisvar. Versão 4. 6 (Build 61) Software.; Lavras: DEX/ UFLA, 2003.

9. Windholz, M.; The Merck Index, Rahway: Merck, 1976. 